\title{
Road Safety Macro Assessment Model: Case Study for Hungary
}

\author{
György Ágoston ${ }^{1 *}$, Radovan Madleňák² \\ ${ }^{1}$ Department of Software Development and Application, University of Dunaújváros, 2400 Dunaújváros, Táncsics M. u. 1/A, Hungary \\ 2 Department of Communications, University of Žilina, Univerzitná 8215/1, 01008 Žilina, Slovakia \\ * Corresponding author, e-mail: agoston@uniduna.hu
}

Received: 04 September 2018, Accepted: 08 October 2018, Published online: 09 January 2020

\begin{abstract}
Road traffic crashes are a considerable concern in motorized countries because of their impact on society, economy. The number of accidents has decreased since 2000. This paper gives an overview of road safety on Hungary's road network and reviews the efforts that were done. Statistical prediction of road traffic crashes is described based on the findings of the scientific literature. Using the data provided by the Hungarian Central Statistical Office for the number of crashes and related factors for the period from 2002 to 2017, a new relationship is established between crashes and a number of related factors in an attempt to improve the models' prediction power and to investigate the effect of adding new predictors on the strength of the models.
\end{abstract}

\section{Keywords}

traffic safety, prediction, traffic accidents

\section{Introduction}

Road traffic accidents are a considerable problem for motorized countries (Hegyi et al., 2017). Accident statistics show a relatively low level of traffic safety in Hungary compared to other developed countries of EU (Ghadi et al., 2018; Kosztolanyi-Ivan et al., 2016). In the European Union, the road accidents are considered as top one death cause in the age group of 45-year and younger ones (Holló and Kiss, 2015). Two major factors that affect traffic accidents are population (Fig. 1 (a)) and motorization (Fig. 1 (b)). Both factors analyzed in this article.

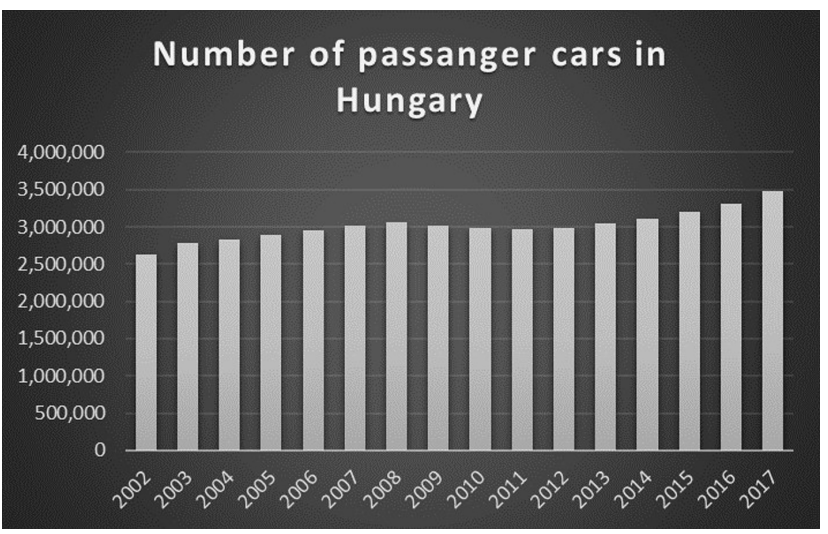

(a)
The population has been decreasing in the investigated period from 10.2 millions to 9.7 millions, meanwhile the number of passenger cars are increasing from 2.6 millions to 3.4 millions (Berta et al., 2018). Many transport policy instrument took place in Worldwide, in EU and in Hungary (Török, 2017) that have significantly contributed to the motorization growth. Motorization as a ration of passenger cars divided by 1000 inhabitants is constantly increasing since 2002 (Fig. 2).

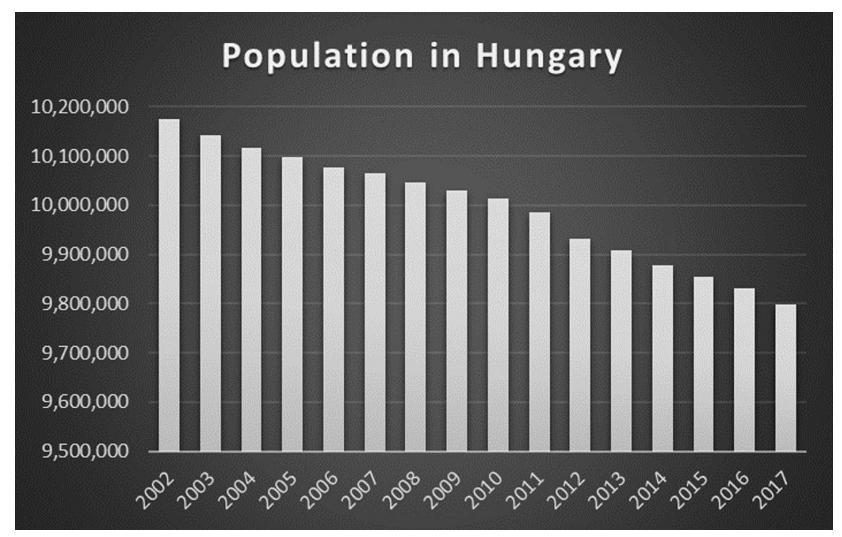

(b)

Fig. 1 (a) Number of passenger cars and (b) inhabitants in Hungary between 2002 and 2017 Source: Hungarian Central Statistical Office 


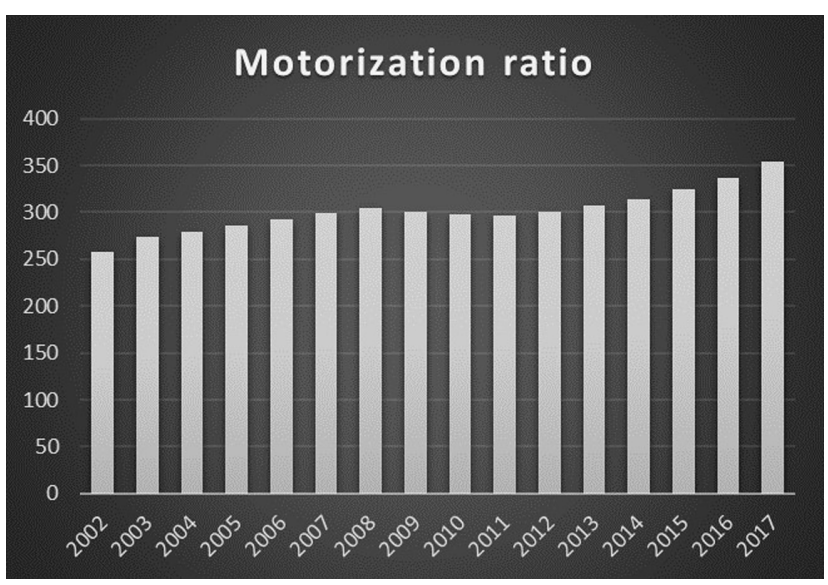

Fig. 2 Evolution of motorization in Hungary between 2002 and 2017 Source: Own edition based on the Hungarian Central Statistical Office

\section{Road safety assessment}

Hungary started to witness a modern motorization development since the 1970s which was reflected on the vehicle ownership and consequently on accidents. Therefore, active political commitment were done against road accidents since early 2000s (Fig. 3).

To be able to compare influencing parameters firstly statistical normalization (Mahalanobis et al., 1937) were calculated. All variables were transformed to 0 average and 1 deviation and then visualized (Fig. 4).

Regression equations in the scientific literature attempt to predict the number of accidents per year and particularly significant employed variables include the Average Daily Traffic (ADT) (Abdel-Aty and Radwan, 2000), paved roadway length (Miaou, 1994), population (Young et al., 1997), number of registered vehicles (Lord et al., 2005) and GDP (Bishai et al., 2006), speed, geometric road parameters (Sipos, 2017), etc.

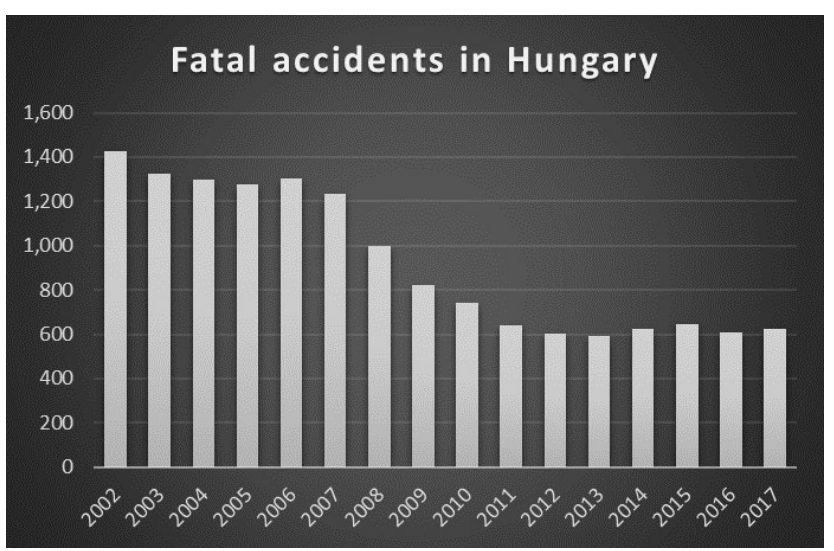

Fig. 3 Fatal accidents in Hungary between 2002 and 2017 Source: Hungarian Central Statistical Office

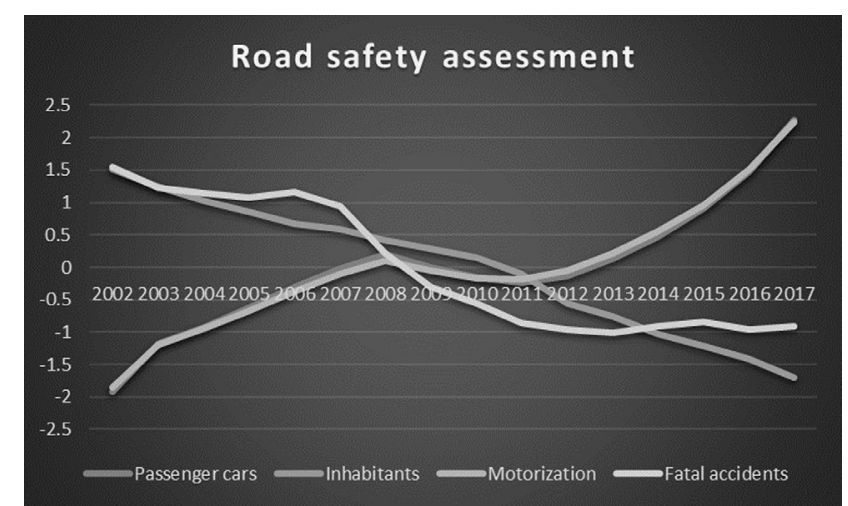

Fig. 4 Road safety assessment between 2002 and 2017 Source: Hungarian Central Statistical Office

The collected data of the number of accidents and related factors covered a period of 15 years from 2002 to 2017 and related to the national road network. The data were provided by the Hungarian Central Statistical Office (Table 1).

\section{Model development}

Section 3 is concerned with developing a multiple linear regression model by which the prediction of number of accidents in Hungary can be achieved.

As can be noticed from the time series data, the number of accidents decreased in the last couple of years.

The regression model for predicting the number of accidents can be expressed in the following form:

$\mathrm{NA}=A+B_{1}(\mathrm{~V})+B_{2}(\mathrm{P})+B_{3}(\mathrm{G})$

Table 1 Road safety assessment normalized data between 2002 and 2017

\begin{tabular}{ccccc}
\hline Year & $\begin{array}{c}\text { GDP } \\
{[\text { USD/inhab. }}\end{array}$ & $\begin{array}{c}\text { Registered } \\
\text { passenger cars }\end{array}$ & $\begin{array}{c}\text { Fatal } \\
\text { accidents }\end{array}$ & $\begin{array}{c}\text { Popula- } \\
\text { tion }\end{array}$ \\
\hline 2002 & -0.772 & -1.915 & 1.542 & 1.517 \\
2003 & -0.630 & -1.180 & 1.228 & 1.240 \\
2004 & -0.509 & -0.925 & 1.137 & 1.021 \\
2005 & -0.383 & -0.625 & 1.082 & 0.858 \\
2006 & -0.193 & -0.301 & 1.158 & 0.679 \\
2007 & -0.086 & -0.010 & 0.942 & 0.590 \\
2008 & 0.169 & 0.205 & 0.224 & 0.413 \\
2009 & 0.168 & -0.002 & -0.305 & 0.290 \\
2010 & 0.304 & -0.150 & -0.555 & 0.148 \\
2011 & 0.498 & -0.231 & -0.865 & -0.096 \\
2012 & 0.537 & -0.140 & -0.966 & -0.555 \\
2013 & 0.745 & 0.132 & -1.008 & -0.753 \\
2014 & 0.928 & 0.465 & -0.902 & -1.021 \\
2015 & 1.087 & 0.909 & -0.847 & -1.207 \\
2016 & 1.134 & 1.488 & -0.960 & -1.421 \\
2017 & -2.998 & 2.279 & -0.905 & -1.702 \\
\hline
\end{tabular}


where:

- NA: The predicted number of accidents,

- $A$ : The constant coefficient of the regression line,

- V: Number of registered vehicles,

- P: Population,

- G: Gross Domestic Product,

- $B_{1}, B_{2}, B_{3}$ : the regression coefficients.

Linear regression analysis was carried out using MS Excel.

The multiple-correlation coefficient $(R)$ reflects the linear correlation between the observed value and the predicted value, it shows how strongly the independent variables can affect the predicted value of accidents. $R^{2}$ is the coefficient of determination which indicates the certainty of making prediction using the model i.e. its prediction power. The high value of $R^{2}$ indicates a high prediction power with $82.4 \%$ of the accidents are due to the selected independent variables included in the model.

The developed model is:

$\mathrm{NA}=-9.49+0.32(\mathrm{~V})+1.16(\mathrm{P})-0.14(\mathrm{G})$.

\section{Model validation and analysis}

Section 4 presents the validation procedure for accident prediction model only. The model resulted in an $F$ statistic value of 24.49 as produced by MS Excel. The critical value of $f=15.05(\alpha=0.05, d f=15)$, since the calculated $F$ is greater than critical $f$, the model is significant at the $5 \%$ significance level.

The multiple linear model allows easily to analyses the factors as the slope of linear terms could easily readable (Table 2).

Based on the results of Table 2 it can be stated that in the investigated period:

- $1 \%$ increase in number of registered passenger cars caused $0.32 \%$ increase in fatal accidents,

- $1 \%$ decrease of in population caused $1.16 \%$ decrease in fatal accidents - please note that there was a continuous decrease of population in the investigated period,

- $1 \%$ increase in economic activity (GDP) caused $0.14 \%$ decrease in fatal accidents - please note the opposite direction of tendencies.

Table 2 Analysis of factors

\begin{tabular}{lcccc}
\hline & Constant $[-]$ & Vehicles & Population & GDP \\
\hline Slope & -9.49 & 0.32 & 1.16 & -0.14 \\
\hline
\end{tabular}

\section{Further research possibilities}

The authors recommend to continue the research in the following three directions:

1. On one hand, the number of deaths not only depends on the Average Daily Traffic, but also on the mileage of vehicles. The investigated period includes the global financial crisis started in 2007. During these years there was a significant decrease in motor mileage in Hungary. More accurate values can be calculated from the domestic gasoline and diesel fuel consumption database, provided by the Hungarian Petroleum Association. It is necessary to evaluate the reduction of fatal accidents taking this into consideration.

2. On the other hand, a special category should also be analyzed. This is the case of cycling deaths and the change of separated cycling route lengths. The reason for this is that unfortunately Hungary was performing the worst place in the EU countries in 2015, in the "Cyclist fatality rates per million populations by country" category (European Commission, 2018). Conclusions can be drawn from the change in length of the separated cycle tracks. The Hungarian Public Road Nonprofit PLC became the official manager of the national bicycle road network and the bicycle routes parallel to the main road in 2018, also provides detailed database information on bike routes.

3. Last, as a result of electromobility as an EU objective, the number of new electric cars, cars with advanced active and passive accident prevention systems and the carsharing service will be increased in the coming decade in Hungary. In the long term, the spread of self-driving cars is also expected. These changes affect the examined parameters $\mathrm{P}, \mathrm{V}$ and G. For a future forecasts these factors also should be analyzed.

\section{Conclusion}

Traffic safety in Hungary was found continuously a serious problem and is growing over the years. Most Hungarians have been personally affected by the trauma of a road accident and the cost to the community in terms of economic loss and personal suffering is enormous. A statistical model that can be used for prediction of the number of fatal accidents on Hungarian roads (NA) was developed. The model is multiple linear regression and incorporates as independent variables the population $(\mathrm{P})$, number of registered vehicles (V) and Gross Domestic Product (G) (see Eq. (2)). 
The model produced a very high $R^{2}$ value of $82.4 \%$ which means that the independent variables included in the model explain $82.4 \%$ of the variations in the accident data. This model is easy to use and able to analyses the effect of parameters on road safety.

Authors are aware of more sophisticated models, but lack of coherent and long term data for Hungary is hardly available.

\section{References}

Abdel-Aty, M. A., Radwan, A. E. (2000) "Modeling traffic accident occurrence and involvement", Accident Analysis \& Prevention, 32(5), pp. 633-642.

https://doi.org/10.1016/S0001-4575(99)00094-9

Berta, T., Abonyi, N., Pauer, G., Török, Á. (2018) "Introduction of the Methodology Focusing on the Implementation of a National Safety Campaign", Periodica Polytechnica Transportation Engineering, 46(1), pp. 17-20.

https://doi.org/10.3311/PPtr.9928

Bishai, D., Quresh, A., James, P., Ghaffar, A. (2006) "National road casualties and economic development", Health Economics, 15(1), pp. 65-81.

https://doi.org/10.1002/hec.1020

European Commission "Traffic Safety Basic Facts on Cyclists", [pdf] European Commission, Directorate General for Transport, June 2018. Available at: https://ec.europa.eu/transport/road_safety/ sites/roadsafety/files/pdf/statistics/dacota/bfs20xx_cyclists.pdf [Accessed: 01 September 2018]

Ghadi, M., Török, Á., Tánczos, K. (2018) "Study of the Economic Cost of Road Accidents in Jordan", Periodica Polytechnica Transportation Engineering, 46(3), pp. 129-134.

https://doi.org/10.3311/PPtr.10392

Hegyi, P., Borsos, A., Koren, C. (2017) "Searching possible accident black spot locations with accident analysis and GIS software based on GPS coordinates", Pollack Periodica, 12(3), pp. 129-140. https://doi.org/10.1556/606.2017.12.3.12

Holló, P., Kiss, D. S. (2015) "How to Deliver the Necessary Data about Serious Injuries to the European Union", Journal of Traffic and Transportation Engineering, 3, pp. 247-253. https://doi.org/10.17265/2328-2142/2015.04.007

Hungarian Central Statistical Office (2018) "Tables (STADAT) - Themes", [online] Available at: http://www.ksh.hu/engstadat?lang=en [Accessed: 01 September 2018]

\section{Acknowledgement}

Authors are greatly acknowledging the support of Adam TOROK Ph.D. and the two independent reviewers for their valuable comments and suggestions.

Kosztolanyi-Ivan, G., Koren, C., Borsos, A. (2016) "Recognition of built-up and non-built-up areas from road scenes", European Transport Research Review, 8(2), Article number: 17. https://doi.org/10.1007/s12544-016-0205-9

Lord, D., Washington, S. P., Ivan, J. N. (2005) "Poisson, Poisson-gamma and zero-inflated regression models of motor vehicle crashes: balancing statistical fit and theory", Accident Analysis \& Prevention, 37(1), pp. 35-46.

https://doi.org/10.1016/j.aap.2004.02.004

Mahalanobis, P. C., Bose, R. C., Roy, S. N. (1937) "Normalisation of Statistical Variates and the Use of Rectangular Co-Ordinates in the Theory of Sampling Distributions", Sankhyā: The Indian Journal of Statistics, 3(1), pp. 1-40.

Miaou, S. P. (1994) "The relationship between truck accidents and geometric design of road sections: Poisson versus negative binomial regressions", Accident Analysis \& Prevention, 26(4), pp. 471-482. https://doi.org/10.1016/0001-4575(94)90038-8

Sipos, T. (2017) "Spatial Statistical Analysis of the Traffic Accidents", Periodica Polytechnica Transportation Engineering, 45(2), pp. 101-105. https://doi.org/10.3311/PPtr.9895

Török, Á. (2017) "Introducing the Methodology of Transplanting a New National Speed Management Strategy", Transport and Telecommunication Journal, 18(2), pp. 118-127. https://doi.org/10.1515/ttj-2017-0011

Young, T., Blustein, J., Finn, L., Palta, M. (1997) "Sleep-Disordered Breathing and Motor Vehicle Accidents in a Population-Based Sample of Employed Adults", Sleep, 20(8), pp. 608-613. https://doi.org/10.1093/sleep/20.8.608 